\title{
Breast Prosthesis Implantation
}

National Cancer Institute

\section{Source}

National Cancer Institute. Breast Prosthesis Implantation. NCI Thesaurus. Code C28336.

Surgical implantation of a breast prosthesis. 